\section{A CASE OF SPINAL TUMOUR IVITH SCOLIOSIS; OPERATION.}

By WILFRED HaRRIS, M.D. Cantab., F.R.C.P. Lond., PHYSICIAN TO ST. MARY'S HOSPITAL; THE HOSPITAL FOR EPILEPSY AND PARALYSIS, MAIDA TALE, ETC.; AND

\section{A. S. BLUNDELL BANKART, M.C. CANTAB.,} F.R.C.S. ENG.,

SURGEON TO THE HOSPITAL FOR EPILEPSY AND PARALYSIS, MIAIDA VALE; THE ROYAL NATIONAL ORTHOPADIC HOSPITAL, ETC.

THE association of lateral curvature of the spine with a tumour compressing the spinal cord does not appear to have been previously recorded.

The patient in the following case was a woman, aged 57 years, who was admitted to the Hospital for Epilepsy and Paralysis, Maida Vale, in September, 1912. She gave no history of previous illness. The first symptoms of her present illness were noticed as far back as 1905, when she complained of weakness and aching in the back. She consulted a medical man, who discovered a dorsal curvature of the spine, and ordered a poroplastic jacket, which she wore until her admission to the hospital. About a year later (1906) she noticed weakness coming on in the legs, and this gradually increased until, three years later (1909), she was unable to walk without assistance. However, she managed to get about indoors until December, 1911, when she took to her bed and remained there up to the time of her admission to the hospital. The paralysis was accompanied by girdle-pain around the lower part of the chest and by loss of sensation in the lower extremities. Also, she complained of a feeling of constriction about the lower limbs and of involuntary jerky movements. From the first the left leg was more affected than the right. In April, 1912, she had retention of urine, and a catheter was passed twice a day for about a month. This then passed off, and there has been no further affection of the sphincters.

On admission to the hospital she was found to have a wellmarked lateral curvature of the spine, with a moderate amount of rotation of the vertebre. The curve, convex to the right, extended from the fifth to the twelfth dorsal vertebra, and the spine above and below it was straight. There was no tenderness over the spinous processes, and no more rigidity than could be accounted for by the fixed scoliosis. There was loss of power in both lower extremities, more complete on the left side than on the right. On the left side paralysis was complete from the hip downwards, and the limb could not be raised from the bed. On the right side all movements were possible but very weak. On both sides the knee-jerk was increased, and there was ankle clonus and extensor plantar reflex. The abdominal reflex was present. Anæsthesia to pin-prick extended in front on the right side up to the level of the xiphoid cartilage ; on the left side two inches lower. Behind it reached to about the level of the ninth or tenth dorsal spinous processes. (The upper limit of anæsthesia, therefore, corresponded with the sensory area of the seventh dorsal segment of the cord.)

Laminectomy was performed on Oct. 7th, 1912. The fourth and fifth dorsal spinous processes and laminæ were removed first. On opening the dura there appeared to be an excess of cerebro-spinal fluid surrounding the spinal cord, and the cord itself looked somewhat smaller than normal, as though it were compressed. A probe passed upwards within the dura met with no resistance. On passing the probe downwards an obstruction was felt about two inches lower. The spine and laming of the sixth dorsal vertebra were then removed, and the incision in the dura extended downwards. A soft pinkish tumour, about the size of a pigeon's egg, was then exposed and found to be adherent to the inner surface of the dura, and compressing the cord on its left posterolateral aspect. It was easily peeled off the cord and removed by blunt dissection. The seventh (or eighth?) posterior nerve-root was adherent to the tumour and was resected. The tumour weighed three grammes, and presented a granular appearance to the naked eye. Microscopically it was a typical endothelioma (psammoma) with the cells everywhere arranged in whorls. One section showed psammoma bodies.

After the operation recovery was uninterrupted, and up to a certain point rapid. In a week the patient was able to appreciate a pin-prick anywhere, and in three weeks all her movements had returned. The finer forms of sensation came back more slowly, and it was several weeks before she was able to stand. She is now able to walk without assistance.

This case is interesting, first, on account of the scoliosis which is a well-recognised accompaniment of some spinal cord diseases, but which, so far as we can discover, has never before been described in association with a spinal tumour. The presence of spinal deformity in this case had led to a diagnosis of arthritic disease of the spine, which was supposed to be causing pressure on the cord, and when seen by us the patient had already been refused operation on that account. But even if spondylitis deformans ever produces compression paraplegia, this case was quite unlike an instance of that disease, for the spinal curve was a typical scoliotic curve, as stiff as such cases often are, but without any of the rigidity of spondylitis. On the other hand, the neurological course and symptoms pointed clearly to pressure of some kind upon the spinal cord, so the patient was sent into the hospital for operation.

Secondly, the situation of the tumour corresponded exactly to the upper limit of demonstrable anæsthesia, which is unusual. The rule is to locate the tumour in the dorsal region one or two segments higher, so as to allow for the overlapping of the sensory areas immediately above. This led to exposure of the cord above the tumour. A much more common mistake is (or used to be) to go too low. Lastly, the very slow rate of growth is worth notice. The first symptoms appeared more than seven years ago, and the legs became affected about a year after the spinal deformity was noticed. But six more years elapsed before the patient was completely disabled. This should indicate a good prognosis.

\section{SOME RESULTS OF FURTHER EXPE- RIENCE WITH SOLID CARBON DIOXIDE.}

By REGINALD MORTON, M.D. TOR., F.R.C.S. EDIN., PRESIDENT, SECTION OF ELECTRO-THERAPEUTICS, ROYAL SOCIETY OF MEDICINE; IN CHARGE OF THE $X$ RAT DEPARTMENT, WEST LONDON HOSPITAL

IT is now about four years since solid carbon dioxide began to be used more or less extensively in this country as a local application for the destruction or removal of superficial adventitious growths or lesions. As might be expected after an interval of three or more years from the introduction of a new therapeutic agent, further experience invariably teaches us to modify the views originally held, sometimes to a very great extent. While carbonic acid snow forms no exception to this rule, it is very likely that few things have given less reason for making any important changes in the ideas first entertained. In fact, it may be said that practically all the claims made in my original paper published in THE LANCET ${ }^{1}$ remain substantially true at the present time. During the last year or so I have had opportunities of seeing a number of my cases treated in the first few months after I began to use it, and it is on account of these that I wish to record such modifications in my former statements as will more accurately correspond with present knowledge.

A word on appliances and methods of preparation. A number of devices have been brought out for facilitating the preparation of the pencils or for preventing unnecessary waste. Some of these have their good points; I have tried most of them at one time or another, but none of them have such distinctive advantages over the method I described at length in my original papers as to make them worth while. As for the question of waste, the material is so cheap that it would take a very long time to save the cost of the apparatus. With a little practice it is quite easy to draw off in a towel almost exactly the amount required for any particular case, and with a few tubes of different sizes in which to mould it, the whole process does not take more than one or two minutes. As for a holder, no form of mechanical clip is really satisfactory, and something better than a strip of lint wound round the crayon two or three times has yet to be designed.

In regard to nævi, carbon dioxide is easily the most useful and efficient agent we possess. It is not suitable for all, but it will give the most satisfactory result in at least 